\title{
Solution for Injection in Multidose Container
}

National Cancer Institute

\section{Source}

National Cancer Institute. Solution for Injection in Multidose Container. NCI Thesaurus.

Code C153625.

Medicinal product consisting of a solution for injection presented in a multidose container. 